\section{Single-file reciprocating system for curved canals preparation: a case report}

\author{
Asrianti, ${ }^{*}$ Nurhayaty Natsir
}

CrossMark
Department of Dental Conservative, Faculty of Dentistry, Hasanuddin University, Makassar, Indonesia

*Corresponding to: Asrianti, Department of Dental Conservative, Faculty of Dentistry, Hasanuddin University, Makassar, Indonesia asriantidrg@yahoo.co.id

Received: 7 June 2018

Revised: 10 June 2018

Accepted: 9 July 2018

Available online 1 August 2018

\title{
Abstract
}

Objective: Preparation of curved canal is the ultimate challenge in endodontic treatment. Various incidents could occur during preparation such as ledges, perforations and zip. Modification instruments have been made to avoid those incidents, can be used according to the canal shape. Reportedly, rotary reciprocating instrument can be used for curved canals because it can maintain canal shape, with or without little alignment. This case report discusses the use of a single file reciprocating system for the preparation of curved canal in the second molar left mandible.

Methods: A 22 years old male patient came to Dental Hospital Hasanuddin University complained about decay of his molar left mandible and felt pain while eating. Radiographic image appears normal at 37 with curved canals in mesial roots and straight canal in distal root along with thickening of periodontal ligament space. Endodontic treatment was performed with preparation of curved canals using rotary Wave One GOLD file in mesial root and Protaper Universal in distal root. Restoration was done with metal onlay.

Results: The results of the preparation maintain the curved canal shape.

Conclusions: Preparation of curved canal using a single file reciprocating system can maintain the original canal shape and bring out good result.

Keywords: Curved canal, Reciprocating system, Single file

Cite this Article: Asrianti, Natsir N. 2018. Single-file reciprocating system for curved canals preparation: a case report. Journal of Dentomaxillofacial Science 3(3): 188-191. D0I: 10.15562/ jdmfs.v3i3.746

\section{Introduction}

Root canal preparation is one of the most important step in any endodontic treatment. ${ }^{1-3}$ Preparation of curved canal is the ultimate challenge in endodontic treatment. ${ }^{4-6}$ Root canal preparation is a procedure to enlarge the root canal using appropriate instrument. The result of the preparation should maintain the canal shape. Good preparation results will facilitate the disinfection procedure by using irrigation materials and facilitates the placement of root canal filling material with proper fluid tight seal. ${ }^{7-10}$

However, curved canals preparations are often difficult witness. Various incidents could occur during preparation such as ledges, perforations, and zip. Modification instruments have been made to avoid those incidents and can be used according to the canal shape. ${ }^{11,12}$

Currently, it has been known that various nickel-titanium (Ni-Ti) rotary instruments are both rotary continuous and rotary reciprocating. This instrument was introduced for faster, safer, efficient, accurate root canal preparation and reduced procedural errors. ${ }^{2,8,11}$

Investigation result exhibited that single-file reciprocating has additional advantages over rotary continuous instrument such as: high flexural cyclic fatigue resistance, lower apical debris extrusion, reduction of cross-contamination possibilities and the ability to finish root canal preparation according to working length with only one instrument. ${ }^{6,13,14}$

Reportedly, rotary reciprocating instrument can be used for curved canals because it can maintain canal shape, with or without little alignment. The WaveOne GOLD system (Dentsply Maillefer, Ballaigues, Switzerland) is one of the instruments included in the single-file reciprocating system. ${ }^{15-18}$

This case report discusses the use of a single-file reciprocating system for the preparation of curved canal in the second molar left mandible.

\section{Case Report}

A 22 years old male patient came to Dental Hospital Hasanuddin University complained about decay of his molar left mandible and felt pain while eating. Previously, the tooth had been treated in the clinic for about 2 months ago but it hadn't been finished. The patient wants his teeth to be treated again and restored. His medical history was normal.

Intra oral examination shows dental caries D6, site 1 size 4 at 37, normal gingiva around the tooth, positive percussion, negative palpation and negative vitality test. Radiographic image appears normal at 37 with curved canals in mesial roots and straight canal in distal root along with thickening of periodontal ligament space. It was diagnosed pulp necrosis with symptomatic apical periodontitis figure 1 . 

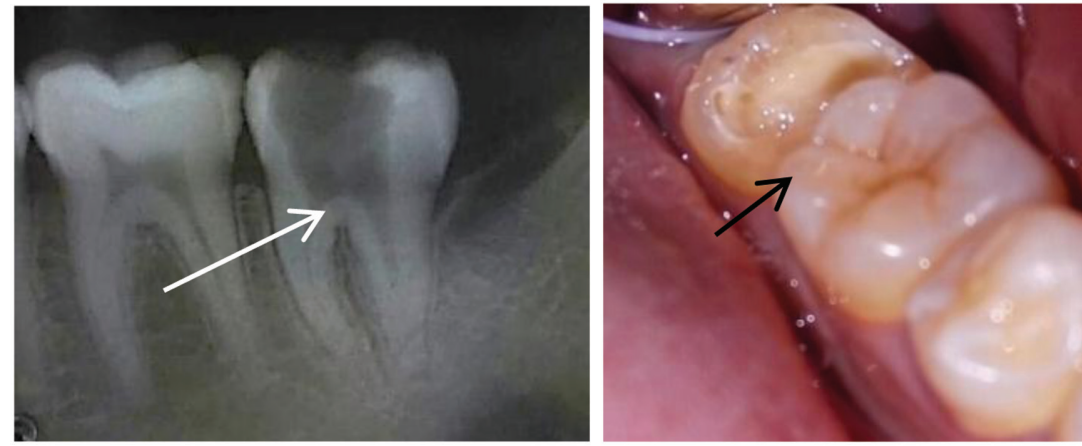

Figure 1 Periapical radiograph and intraoral photograph

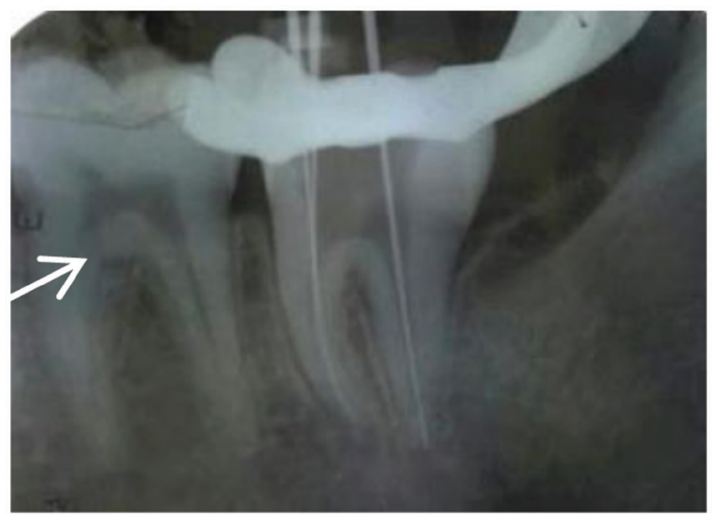

Figure 2 Determine of working length

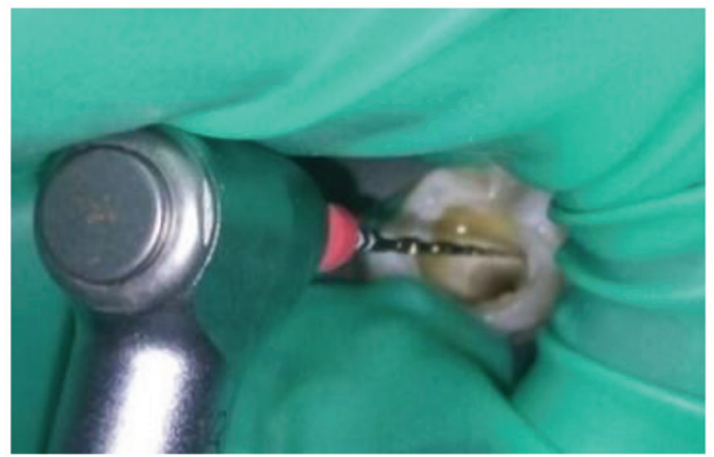

Figure 3 Preparation with single-file Wave One GOLD primary

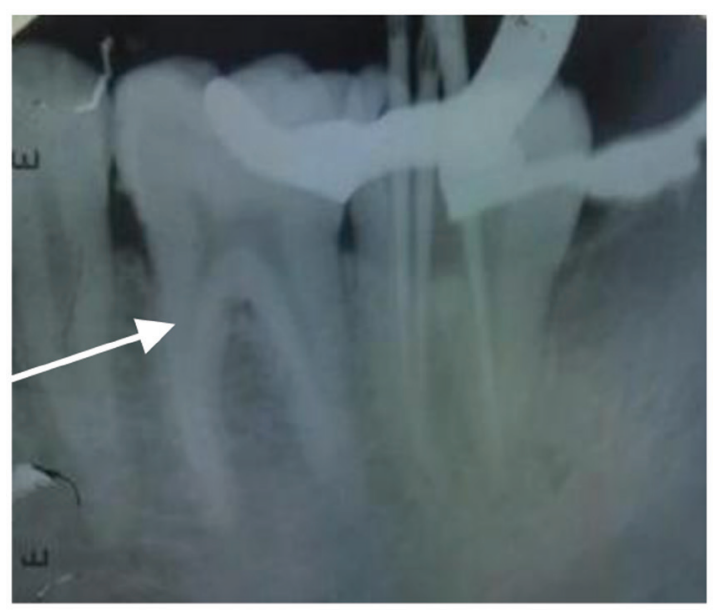

Figure 4 Try-in gutta-percha

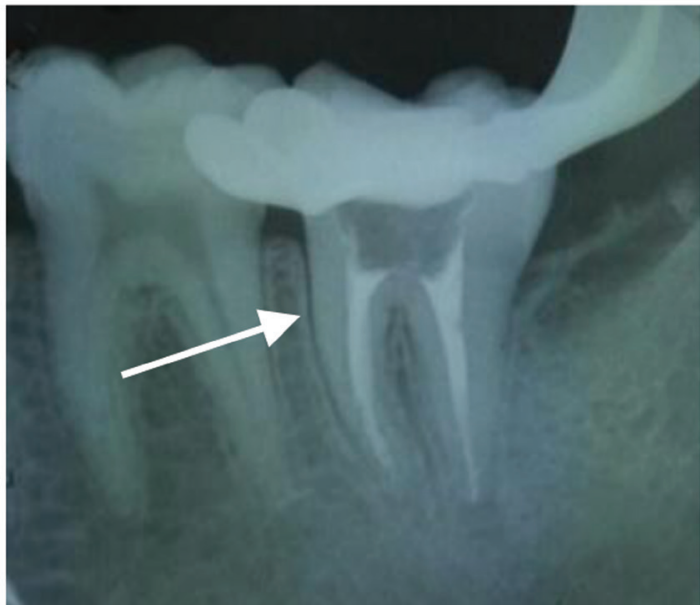

Figure 5 Obturation of root canals

Access opening was performed and prepared up to $2 / 3$ coronal in mesial root using primary size single-file rotary Wave One GOLD (Dentsply Maillefer, Ballaigues, Switzerland) following the proGlider (Dentsply) with lubricant and \#S1-\#S2 protaper universal (Dentsply) in distal root. The working length was determined with electronic apex locator (Proper Pixi, Dentsply Maillefer, Ballaigues, Switzerland) and verified with a periapical radiograph (mesiobuccal; $17 \mathrm{~mm}$, mesiolingual: $18 \mathrm{~mm}$ and distal: $18 \mathrm{~mm}$ ) figure 2. The preparation was continued in mesial root by using a primary size single-file rotary Wave One GOLD figure 3 following the proglider with lubricant and \#S1- \#F2 protaper universal in distal root according to the working length. Irrigation was carried out with $2.5 \%$ sodium hypochlorite and aquadest during instrumentation and recapitulated with a \#10 K-file. Trial photograph with gutta-percha figure 4, medicament administration then temporarily restored.

On the second visit, irrigation was performed then dried and obturation was done by single cone technique in mesial canal and lateral condensation in distal canal. The obturation of root canals were evaluated with a periapical radiographfigure 5 then application of glass ionomer cements and temporarily restored. All metal onlay restoration procedure is performed on the next visit.

\section{Discussion}

The final result of curved canals preparation may be influenced by various factors such as flexibility and diameter of the endodontic instruments, preparation techniques and the hardness of dentin. ${ }^{4}$ The final result of preparation should be in the form of a progressive tapered. A progressive taper of canal allows better instrumentation and irrigation materials can be well contacted on the canal wall with the result of more effective cleaning. ${ }^{2,10,14}$ 
The preparation of curved canals are often a failure mainly due to procedural errors such as ledges, perforations, zip and instrument fractures. ${ }^{4,7,12}$ Therefore, the selection of appropriate instruments is important for the preparation of curved canal. ${ }^{17,19,20}$ Wave One GOLD is one of the instruments with design innovation, manufacturing process, and thermo-mechanical treatment on alloy has been developed to increase fatigue failure resistance and provides greater safety during canal preparation..$^{18,21}$

Wave One GOLD is the newest generation of simplicity, safety and single use reciprocating files for root canal preparation. Wave One GOLD system technology can increase cyclic fatigue resistance, instrument flexibility and canal centering ability. Thus, this instrument is trusted to avoid the occurrence of procedural errors when used for the preparation of teeth with curved canals. ${ }^{18}$

Wave One GOLD single-file systems are designed to cut the dentin in a 150-degree Counter Clock Wise (CCW) direction and then, rotate back toward 30-degrees Clock Wise (CW) direction, before the instrument has chance to taper lock. The net file movement is cutting cycles of 120 degree and therefore after three cycles the file will have made a reverse rotation of 360 degrees. This file is used in a brushing action which can reduce the contact between the file and dentine, prevent undesirable taper lock and allows the instrument to move more freely. ${ }^{1,8,18}$

In this case, preparation using Wave One GOLD primary file in mesial canal following the ProGlider to create a glide path. This file is used with gentle inward pressure that allows passively moving files into the root canal. The Wave One GOLD primary file will create optimal shape of preparation in approximately $80 \%$ of canals as a true single-file technique. After the primary file reaches its working length and the flute is fully loaded with debris, this indicates that the preparation is finished. ${ }^{18}$

Overall, these single-file reciprocating system design features result in a reciprocating movement that is very smooth, eliminating the need to push on the file, and thereby promoting safety and considerably improving cutting efficiency so as to reduce preparation time. Studies have shown that the preparation using single-file reciprocating system is four times safer and three times faster than the rotary continuous file and it has been reported that this instrument has high flexibility and centering ability so as to maintain the original canal shape with minimal transportation when used for the preparation of curved canals.,14

\section{Conclusion}

The preparation of curved canal requires the selection of appropriate instrument. Single-file reciprocating system is the choice instrument for curved canals preparation because it's ability to maintain the original canal shape and less procedural errors so as to prevent the occurrence of ledge, zip, perforation and fractured instruments.

\section{Acknowledgment}

The author would like to thank to the supervisor of Department of Conservative Dentistry, Faculty of Dentistry, Hasanuddin University and staffs for us to conduct this case report.

\section{Conflict of Interest}

The authors report no conflict of interest.

\section{References}

1. Grande NM, Plotino G, Ahmed HMA, et al. The reciprocating movement in endodontics. Endod practice 2016: 28-33.

2. Dhingra A, Ruhal N, Miglani A. Evaluation of single-file systems reciproc, oneshape, and WaveOne using cone beam computed tomography-an in vitro study. J Clin Diagn Res 2015;9: 30-34.

3. Amaral P, Forner L, Llena C. Smear layer removal in canals shaped with reciprocating rotary systems. J Clin Exp Dent 2013;5: 227-230.

4. Darmiani S, Bidabadi MM. Root canal treatment in a dilacerated maxillary first molar: a case report. IJDR 2014;2: 14-15.

5. Saber SEDM, Nagy MM, Schafer E. Comparative evaluation of the shaping ability of WaveOne, Reciproc and oneShape single-file systems in severely curved root canals of extracted teeth. Int Endod J 2014: 1-6.

6. Villela AM, Kato AS, Rios MA, et al. Fracture incidence of reciproc instruments in endodontic treatment provided by graduate students-a retrospective study. J Dent Oral Health 2017;3: 2-4.

7. Chole D, Burad PA, Kundoor S, et al. Canal transportation-a threat in endodontics: a review. IOSR-JDMS 2016;15: 64-72.

8. Alsilani R, Jadu F, Alhazzazi TY. Single file reciprocating systems: a systematic review and meta-analysis of the literature: comparison of reciproc and WaveOne. J Int Soc Prev Com Dent 2016;6: 402-409.

9. Goenawan M, Nugroho JJ, Rovani CA, et al. Effectivity of convex triangular and rectangular cross section instruments on decreasing the amount of root canal enterococcus faecalis bacteria colonies. J Dentomaxillofac Sci 2016;1: 113-117.

10. Hargreaves KM, Berman LH, Rotstein I. Cohen's pathways of the pulp. 11th ed. St Louis: Elsevier; 2011. p. 209-213.

11. Aracena D, Betancourt P, Borie E, et al. Waveone: a simple and safe way to perform an endodontic treatment. Int J Odontost 2014;8: 207-210.

12. Vieira CAJ, Dessaune NN, Costa RVR, et al. Transportation assessment in simulated curved canals after preparation with twisted file adaptive and bt-race instruments. J Clin Exp Dent 2017;9: 1136-1140. 
13. Sharma P, Goel M, Verma S, et al. entering a new era in endodontics with revolutionary single file systems: A comprehensive review. EC Dental Sci 2016;5: 1100-1122.

14. Parimoo D, Gupta R, Tomer A, et al. Single file endodontics: boon or myth? Asian Pac J Health Sci 2016;3: 102-105.

15. Dhingra A, Srivastava P, Chadda D, et al. Simplify your endodontics with single file systems case reports. IOSRJDMS 2013;6: 44-51.

16. Van-der, Vyver PJ, Jonker C. Clinical review reciprocating instruments in endodontics: a review of the literature. SADJ 2014;69: 404-409.

17. D’Amario M, De Angelis F, Mancino M, et al. Canal shaping of different single-file systems in curved root canals. J Dent Sci 2017;12: 328-332.

18. Webber J. Shaping canals with confidence: Wave One GOLD single-file reciprocating system. Int Dentist African ed 2015;6: 6-17.
19. Ansari I, Maria R. Managing curved canals. Contemp Clin Dent 2012;3: 237-241.

20. Mossa AM, Al-Hamer N, AL-Ghatam R. Endodontic treatment of a first mandibular molar with severely curved roots. IJPCDR 2017;4: 1-3.

21. Elsaka SE, Elnaghy AM, Badr AE. Torsional and bending resistance of Wave One Gold, Reciproc and Twisted File Adaptive instruments. Int Endod J 2017;50: 1077-1083.

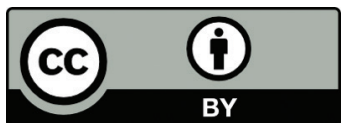

This work is licensed under a Creative Commons Attribution 